\title{
Static Reliability Analysis of Prestressed Concrete V - Shaped Continuous Beam Bridge
}

\author{
Le-ping Ren ${ }^{1, a}$, Wen-liang Hu ${ }^{1, b}$, Sheng-wei Liang, ${ }^{1, c}$ \\ ${ }^{1}$ College of Highway, Chang'an University, Xi'an 710064, Shanxi, China
}

Keywords: V-shaped Continuous Beam; First Order Two Moment Method; Reliability; Parameters

\begin{abstract}
In this paper, the reliability theory of engineering structure based on a city landscape bridge (multi span prestressed concrete V-shaped pier continuous beam bridge) as engineering background, key section of main girder and V-shaped pier of continuous girder bridge of prestressed concrete V-shaped pier by using the first two order moment method to evaluate the bridge girder and the shape of V-pier bridge reliability index, reflect design intent; and the influence of various factors on the reliability index of sensitivity analysis in the design reference period of resistance of this kind of bridge reliability greatly. The influence of the variation of the dead load on the reliability of the main beam is negligible, but it has great influence on the reliability of the $\mathrm{V}$-shaped pier. The effect of live load effect on the reliability of the main beam is very significant, and the effect on the reliability of $\mathrm{V}$ - shaped pier is small. Therefore, this study has certain engineering value for the design, operation, maintenance and monitoring of the multi span prestressed concrete V-shaped pier continuous beam.
\end{abstract}

\section{Introduction}

In recent years, V-shaped pier continuous beam, as a unique bridge structure system, has been widely used in urban landscape bridges because of its unique structure, shape and force mode. The substructure adopts V-shaped pier, with the same span straight continuous girder bridge pier or span continuous rigid frame bridge girder calculation is reduced, compared to the negative moment in beam position greatly reduced, at the same time in the positive moment across the site also reduced [1 2]. However, at the same time, the key section of the main girder and the V-shaped pier is often caused by the excessive bending moment, which results in the failure of the section strength. Scholars at home and abroad have studied the static and dynamic problems of prestressed concrete V-shaped pier bridge [3 5], but the reliability of this kind of bridge is relatively less. Therefore, it is necessary to study the reliability of $\mathrm{V}$-shaped pier continuous beam bridge.

The main girder and the V-shaped pier are the main components of the V-shaped pier continuous girder bridge. In the study of reliability of such bridges, the reliability analysis of the main beam and the V-shaped pier is necessary. Jiang Zhengwen [6] combined the Monte-Carlo method and response surface method to analyze the static reliability of the continuous rigid frame bridge. Liu Yang et al. [7 8] used adaptive Monte-Carlo method to study the reliability of long-span continuous rigid frame bridge construction, and the response surface method was used to analyze the system reliability of the continuous rigid frame bridge. According to the characteristics of structural failure of continuous beam bridge, Zhang Yeping [9] put forward a method for analyzing the reliability of such bridges.

The first order-second moment method (JC method) is one of the main calculation methods of bridge structure reliability. The method [10] can be considered the actual distribution of the random variable by "equivalent normalized", non-normal distribution of the normalized variable; at the design point checking function according to the state of the Taylor series expansion; finally calculated reliably index. The method is widely used by the Joint Committee on International Structural Safety (JCSS) due to its operability and its accuracy to meet the engineering needs. According to the characteristics of V-shaped continuous beam bridge, JC method is used to analyze the reliability index of main beam and V-shaped pier. The resistance and effect parameters used in the limit state equation are composed of bending moment, dead load and live load generated by the 
main section. Respectively, Calculating the reliability index of the main beam edge of the four points, $\mathrm{V}$-shaped pier of the main beam across the middle and secondary cross across the middle cross section in the cross section and V-shaped pier top, the bottom section. At the same time, the sensitivity of the random variable parameters was analyzed to study the influence degree of the reliability index on the main beam and V-shaped pier.

\section{Project Overview}

A city landscape bridge is a five-span V-shaped continuous beam system with a span of $55+90$ $+90+90+55=380 \mathrm{~m}$. The superstructure of the main bridge is arranged symmetrically along the centerline of the main span, and the left and right sides are 1.5\%, as shown in Fig 1 . The main beam cross-section of the form of a single box with four rooms, a single full width of $22.5 \mathrm{~m}$, V-shaped pier using trapezoidal box chamber structure, edge V-shaped pier of the top of the theoretical span of $37 \mathrm{~m}$, in the V-top beam theoretical span of $39 \mathrm{~m}$. The deck is arranged for $3 \mathrm{~m}$ crosswalk $+3.5 \mathrm{~m}$ non-motorized road $+0.5 \mathrm{~m}$ partition $+15 \mathrm{~m}$ motorway $+0.5 \mathrm{~m}$ crash barrier. V-shaped pier with reinforced concrete structure, V-shaped pier lope large and high height, in order to reduce the weight, improve the force, $\mathrm{V}$-shaped pier structure with a part of the hollowed out of the single-box four-chamber cross-section, V-shaped pier box web and the main beam box Web center line one to one correspondence. The middle beam connects the V-shaped pier with the main beam. V-shaped pier at the bottom of the set of bearings.

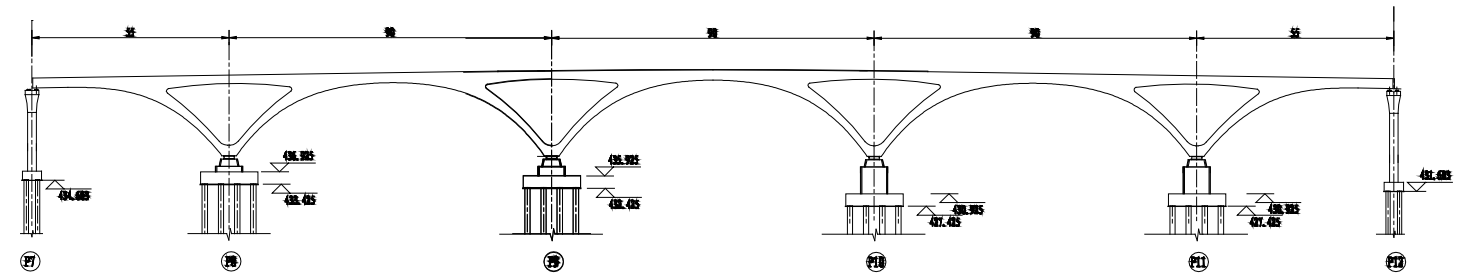

Fig.1. General arrangement(unit:m)

\section{Calculation of reliability of main girder and $\mathrm{V}$-shaped pier}

For the V-shaped pier continuous girder bridge, there are two main types of static failure modes for the main girder and the V-shaped pier. They are the control of the key section, the bending failure and the control of the shear failure of the key section. This paper analyzes the former. In the structure of the limit state equation, resistance selection sectional resistance moment, dead load and live load effect selection (such as automobile and crowd load) under the action of bending moment. According to the reliability theory of engineering structure, first order second moment method (JC method) is used to calculate the reliability index of the critical section of the V-shaped pier.

Establishment of limit state equation of $\mathrm{V}$ pier continuous beam bridge

The load of bridge is complex and varied, but it can be divided into two types: dead load and live load. Dead load mainly includes self-weight, secondary dead load, etc .; live load, including cars, crowds and other loads. As for the purpose of this paper, the load effect only considers dead load and automobile load. Therefore, the limit state equation is:

$$
Z=M_{R}-M_{G}-M_{Q}
$$

In the formula, $M_{R}$ is the main beam and $\mathrm{V}$-shaped piers, and the distribution type is lognormal distribution; $M_{G}$ is the bending moment of the dead load, the distribution type is normal distribution; $M_{Q}$ is the bending moment of the vehicle load, the distribution type is Maximum value type I distribution.

\section{Solution of limit state equation}

Because of the limit state equation, the section force and live load effect for the non-normal distribution, the reliability index calculation method is more trouble, so this paper use first order second moment method (JC method) to calculate the reliability index of V-shaped pier continuous 
girder bridge.

The basic principle of JC method is to convert the basic random variables of each distribution into the standard normal space, and use the tangent plane at the design verification point instead of the limit state surface reliability index which is the origin of coordinates of standard normal coordinate system to cut the shortest distance plane.

Based on the reliability theory of engineering structure, the reliability index of the V-shaped continuous beam bridge is calculated, and the distribution type, mean value and standard deviation of the relevant random variables are shown in Table 1 and Table 2. The statistical parameters of each random variable Reference [11]. The first order second moment method (JC method) is used to calculate the reliability index of the side span at $1 / 4$ points; the middle span of $\mathrm{V}$-shaped pier top girder; middle span of secondary span; middle span girder section; V-shaped pier top section; V-shaped pier bottom cross section. V-shaped pier control section shown in Figure 2.

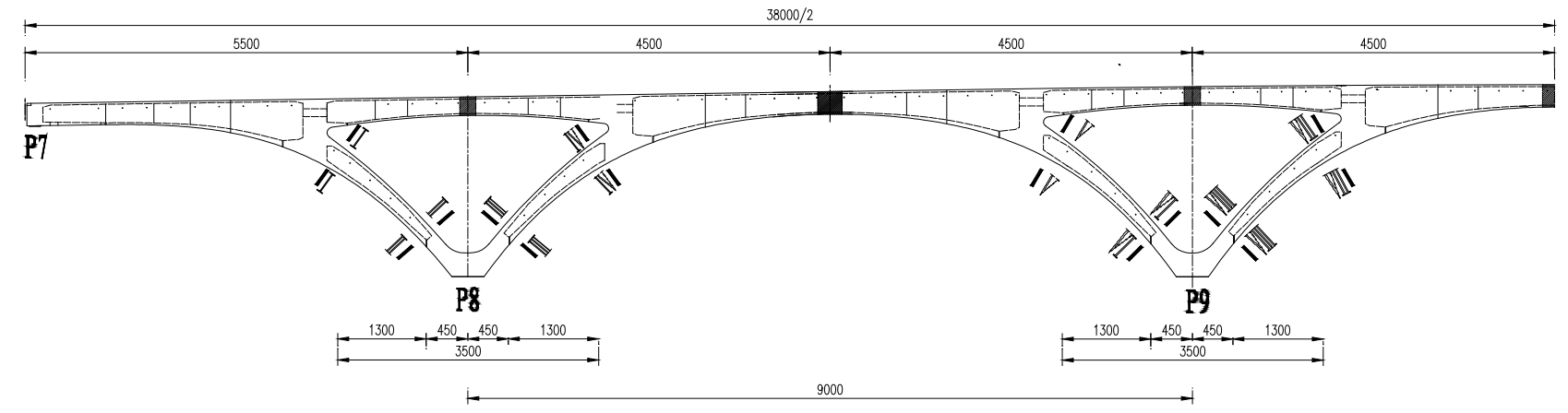

Fig.2. V-shaped pier control section(unit:cm)

Tab.1. Table of statistical parameters of random variables of main beam

\begin{tabular}{|c|c|c|c|c|c|}
\hline $\begin{array}{c}\text { The Main beam controls the } \\
\text { cross section position }\end{array}$ & Variable & $\begin{array}{c}\text { Probability } \\
\text { distributions }\end{array}$ & Mean & $\begin{array}{c}\text { Standard } \\
\text { deviation }\end{array}$ & $\begin{array}{c}\text { Coefficient } \\
\text { of variatio }\end{array}$ \\
\hline \multirow{4}{*}{ 0.25L of Side span } & $M_{R}$ & Lognormal & 76766.62 & 10854.80 & 0.1414 \\
\cline { 2 - 6 } & $M_{G}$ & Normal & 27833.93 & 1199.64 & 0.0431 \\
\cline { 2 - 6 } & $M_{Q}$ & $\begin{array}{c}\text { Type I extreme } \\
\text { value }\end{array}$ & 13825.87 & 1191.50 & 0.0862 \\
\hline \multirow{4}{*}{ Side V-shaped pier } & $M_{R}$ & Lognormal & 74614.02 & 10550.42 & 0.1414 \\
\cline { 2 - 6 } & $M_{G}$ & Normal & 26906.10 & 1159.653 & 0.0431 \\
\cline { 2 - 6 } Middle of secondary span & $M_{Q}$ & $\begin{array}{c}\text { Type I extreme } \\
\text { value }\end{array}$ & 6498.02 & 559.99 & 0.0862 \\
\cline { 2 - 6 } & $M_{R}$ & Lognormal & 73700.14 & 10421.20 & 0.1414 \\
\cline { 2 - 6 } & $M_{G}$ & Normal & 27339.02 & 1178.312 & 0.0431 \\
\hline \multirow{4}{*}{ Middle of V-shaped pier } & $M_{Q}$ & Type I extreme & 15128.97 & 1303.80 & 0.0862 \\
\cline { 2 - 6 } & $M_{G}$ & vognormal & 77753.96 & 10994.41 & 0.1414 \\
\cline { 2 - 6 } & $M_{Q}$ & $\begin{array}{c}\text { Type I extreme } \\
\text { value }\end{array}$ & 6770.01 & 583.43 & 0.0862 \\
\hline \multirow{4}{*}{ Middle of midspan } & $M_{R}$ & Lognormal & 63301.96 & 8950.90 & 0.1414 \\
\cline { 2 - 6 } & $M_{G}$ & Normal & 8618.29 & 371.4483 & 0.0431 \\
\cline { 2 - 6 } & $M_{Q}$ & $\begin{array}{c}\text { Type I extreme } \\
\text { value }\end{array}$ & 17330.77 & 1493.55 & 0.0862 \\
\hline
\end{tabular}


Tab.2. Table of statistical parameters of random variables of V-shaped pier

\begin{tabular}{|c|c|c|c|c|c|}
\hline $\begin{array}{l}\text { V-shaped piers section } \\
\text { position }\end{array}$ & Variable & $\begin{array}{c}\text { Probability } \\
\text { distributions }\end{array}$ & Mean & $\begin{array}{l}\text { Standard } \\
\text { deviation }\end{array}$ & $\begin{array}{c}\text { Coefficient of } \\
\text { variatio }\end{array}$ \\
\hline \multirow{3}{*}{ I - I } & $M_{R}$ & Lognormal & 140827.84 & 19913.06 & 0.1414 \\
\hline & $M_{G}$ & Normal & 60203.82 & 2592.54 & 0.0431 \\
\hline & $M_{Q}$ & $\begin{array}{c}\text { Type I extreme } \\
\text { value }\end{array}$ & 14110.78 & 1216.05 & 0.0862 \\
\hline \multirow{3}{*}{ II -- II } & $M_{R}$ & Lognormal & 52783.50 & 7463.59 & 0.1414 \\
\hline & $M_{G}$ & Normal & 20520.37 & 883.66 & 0.0431 \\
\hline & $M_{Q}$ & $\begin{array}{c}\text { Type I extreme } \\
\text { value }\end{array}$ & 5309.88 & 457.60 & 0.0862 \\
\hline \multirow{3}{*}{ III-III } & $M_{R}$ & Lognormal & 58140.15 & 8221.02 & 0.1414 \\
\hline & $M_{G}$ & Normal & 23424.32 & 1008.71 & 0.0431 \\
\hline & $M_{Q}$ & $\begin{array}{l}\text { Type I extreme } \\
\text { value }\end{array}$ & 5718.74 & 492.83 & 0.0862 \\
\hline \multirow{3}{*}{ IV-IV } & $M_{R}$ & Lognormal & 147404.69 & 20843.02 & 0.1414 \\
\hline & $M_{G}$ & Normal & 67938.83 & 2925.63 & 0.0431 \\
\hline & $M_{Q}$ & $\begin{array}{c}\text { Type I extreme } \\
\text { value }\end{array}$ & 11333.31 & 976.69 & 0.0862 \\
\hline \multirow{3}{*}{$V-V$} & $M_{R}$ & Lognormal & 155349.49 & 21966.42 & 0.1414 \\
\hline & $M_{G}$ & Normal & 76337.32 & 3287.29 & 0.0431 \\
\hline & $M_{Q}$ & $\begin{array}{c}\text { Type I extreme } \\
\text { value } \\
\end{array}$ & 13186.71 & 1136.42 & 0.0862 \\
\hline \multirow{3}{*}{ VI-VI } & $M_{R}$ & Lognormal & 62332.53 & 8813.82 & 0.1414 \\
\hline & $M_{G}$ & Normal & 29060.22 & 1251.41 & 0.0431 \\
\hline & $M_{Q}$ & $\begin{array}{l}\text { Type I extreme } \\
\text { value }\end{array}$ & 5034.37 & 433.86 & 0.0862 \\
\hline \multirow{3}{*}{ VIII-VII } & $M_{R}$ & Lognormal & 64707.19 & 9149.60 & 0.1414 \\
\hline & $M_{G}$ & Normal & 30374.08 & 1307.99 & 0.0431 \\
\hline & $M_{Q}$ & $\begin{array}{c}\text { Type I extreme } \\
\text { value }\end{array}$ & 5234.81 & 451.13 & 0.0862 \\
\hline \multirow{3}{*}{ VIII-VIII } & $M_{R}$ & Lognormal & 150557.25 & 21288.80 & 0.1414 \\
\hline & $M_{G}$ & Normal & 74460.85 & 3206.48 & 0.0431 \\
\hline & $M_{Q}$ & $\begin{array}{c}\text { Type I extreme } \\
\text { value }\end{array}$ & 12331.97 & 1062.75 & 0.0862 \\
\hline
\end{tabular}

Tab.3. Calculation results of reliability of main girder section

Reliability index of main beam section position

\begin{tabular}{|c|c|c|c|c|}
\hline $\begin{array}{c}\text { 0.25L of Side } \\
\text { span }\end{array}$ & $\begin{array}{c}\text { Side V-shaped } \\
\text { pier }\end{array}$ & $\begin{array}{c}\text { Middle of secondary } \\
\text { span }\end{array}$ & $\begin{array}{c}\text { Middle of V-shaped } \\
\text { pier }\end{array}$ & $\begin{array}{c}\text { Middle of } \\
\text { midspan }\end{array}$ \\
\hline 4.1348 & 5.4679 & 3.7220 & 5.6783 & 5.4086 \\
\hline
\end{tabular}

Tab.4 Calculation results of reliability of V-shaped pier

Reliability index of V-shaped piers section position

\begin{tabular}{|c|c|c|c|c|c|c|c|}
\hline \multicolumn{7}{|c|}{ Reliability index of V-shaped piers section position } \\
\hline I - I & II - II & III-III & IV-IV & V - V & VI-VI & VII-VII & VIII-VIII \\
\hline 4.3387 & 4.8575 & 4.6922 & 4.2018 & 3.7279 & 4.0863 & 4.0445 & 3.7245 \\
\hline
\end{tabular}


Through the calculation of the reliability of the section of the main girder and the V-shaped pier, the greater the bending moment of the key section of the main girder, the greater the reliability index. But for the critical section of V-shaped pier, the reliability index of V-shaped top section is lower than that of bottom section. At the same time, in the highway bridge reinforced concrete and prestressed reinforced concrete structure of the normal use of the limit state, $\beta$ value is usually between 1.0 to 2.0 [12]. By calculation, the minimum reliability index of the key section of main girder of the bridge is 3.7220, the minimum reliability index of V-shaped pier key section 3.7245, the V-shaped pier of continuous girder bridge key flexural reliability index is greater than the reliability index of ductility damage component reliability specification [13] in the minimum required 3.7.

\section{Parameter Sensitivity Analysis}

In order to understand the influence degree of parameters of each random variable of structure, it is necessary to do parameter sensitivity analysis for each random variable and calculate sensitivity coefficient. The sensitivity coefficient can reflect the weight of the influence of the change of each random variable on the reliability, and the greater the absolute value of the value, the more obvious the influence of the random variable on the reliability. In this paper, the influence of resistance and load effect parameters on the reliability of V-shaped pier continuous girder bridge is analyzed by taking the middle section of midspan and the middle V-shaped VIII-VIII section as an example.

\section{Effect of coefficient of resistance variation on reliability}

As the resistance coefficient of bridge components is affected by factors such as material properties and geometrical parameters and reinforcement ratio. Therefore, in order to study the effect of resistance coefficient of variation on the reliability, the coefficient of variation coefficient of cross-section resistance is in the range of $0.1414 \sim 0.3414 / 0.05$. The second-order moment method is used to calculate the reliability index of $\mathrm{V}$-shaped continuous beam bridge. The results are shown in Table 5 and Table 6.

Tab.5. Resistance parameter analysis of main girder section

\begin{tabular}{|c|c|c|c|c|c|c|}
\hline \multicolumn{2}{|c|}{ Coefficient of variatio } & 0.1414 & 0.1914 & 0.2414 & 0.2914 & 0.3414 \\
\hline \multirow{3}{*}{ Sensitivity coefficient } & $\alpha_{M_{R}}$ & -0.7439 & -0.8991 & -0.9567 & -0.9751 & -0.9834 \\
\cline { 2 - 7 } & $\alpha_{M_{G}}$ & 0.0552 & 0.0597 & 0.0545 & 0.0475 & 0.0417 \\
\cline { 2 - 7 } & $\alpha_{M_{Q}}$ & 0.6660 & 0.4338 & 0.2859 & 0.2164 & 0.1767 \\
\hline \multicolumn{2}{|c|}{ Reliability index $\beta$} & 5.4086 & 4.3747 & 3.5497 & 2.9519 & 2.5111 \\
\hline
\end{tabular}

Tab.6. Resistance parameter analysis of V-shaped pier

\begin{tabular}{|c|c|c|c|c|c|c|}
\hline \multicolumn{2}{|c|}{ Coefficient of variatio } & 0.1414 & 0.1914 & 0.2414 & 0.2914 & 0.3414 \\
\hline \multirow{3}{*}{ Sensitivity coefficient } & $\alpha_{M_{R}}$ & -0.9661 & -0.9805 & -0.9873 & -0.9911 & -0.9934 \\
\cline { 2 - 7 } & $\alpha_{M_{G}}$ & 0.2452 & 0.1876 & 0.1517 & 0.1275 & 0.1101 \\
\cline { 2 - 7 } & $\alpha_{M_{Q}}$ & 0.0813 & 0.0591 & 0.0468 & 0.0388 & 0.0333 \\
\hline \multicolumn{2}{|c|}{ Reliability index $\beta$} & 3.7245 & 2.7638 & 2.1757 & 1.7776 & 1.4890 \\
\hline
\end{tabular}




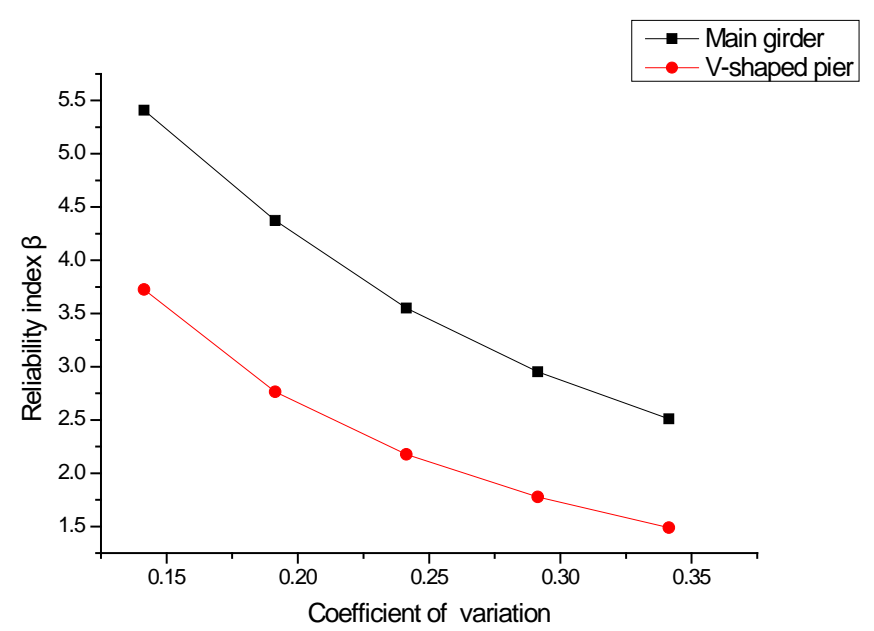

Fig.3. Parameter analysis of section resistance

It can be seen from Fig. 3 that the reliability index of the critical section of V-shaped continuous beam bridge decreases with the increase of the coefficient of variation of cross-section resistance. The reliability index of the key section of $\mathrm{V}$ - shaped pier continuous girder and $\mathrm{V}$ - shaped pier is reduced by more than 50\%. From the sensitivity coefficient, with the increase of the coefficient of variation of cross-section resistance, the influence degree of the main beam and V-shaped piers cross section resistance on the reliability index gradually increased and dominated. Considering the causes of variability of cross-section resistance, there are the uncertainty of material properties, the uncertainty of cross-section geometric parameters and the uncertainty of the calculation model. However, in the actual construction process, the site environment, curing conditions and construction technology and other factors, making the cross-section resistance variability. Therefore, in the construction of such bridges, especially for the V-shaped pier construction, to strengthen the quality of materials and construction technology strictly control, thereby reducing the cross-section resistance variability, improve the bridge structure reliability index.

\section{Effect of variation coefficient of dead load on reliability}

In order to study the effect of the coefficient of variation of the dead load on the reliability, the coefficient of variation of the dead load is in the range of 0.0431 to $0.2431 / 0.05$. The first order-second moment method is used to calculate the reliability index of V-shaped continuous beam bridge. The results are shown in Table 7 and Table 8.

Tab.7. Parameter analysis of the dead load effect of the main beam

\begin{tabular}{|c|c|c|c|c|c|c|}
\hline \multicolumn{2}{|c|}{ Coefficient of variatio } & 0.0431 & 0.0931 & 0.1431 & 0.1931 & 0.2431 \\
\hline \multirow{3}{*}{ Sensitivity coefficient } & $\alpha_{M_{R}}$ & -0.7439 & -0.7468 & -0.7516 & -0.758 & -0.7651 \\
\cline { 2 - 7 } & $\alpha_{M_{G}}$ & 0.0552 & 0.1196 & 0.1846 & 0.2504 & 0.3167 \\
\cline { 2 - 7 } & $\alpha_{M_{Q}}$ & 0.666 & 0.6542 & 0.6333 & 0.6023 & 0.5606 \\
\hline \multicolumn{2}{|c|}{ Reliability index $\beta$} & 5.4086 & 5.3784 & 5.3261 & 5.2517 & 5.1558 \\
\hline
\end{tabular}

Tab.8. Parameter analysis of the dead load effect of V-shaped pier

\begin{tabular}{|c|c|c|c|c|c|c|}
\hline \multicolumn{2}{|c|}{ Coefficient of variatio } & 0.0431 & 0.0931 & 0.1431 & 0.1931 & 0.2431 \\
\hline \multirow{3}{*}{ Sensitivity coefficient } & $\alpha_{M_{R}}$ & -0.9661 & -0.8904 & -0.8112 & -0.7399 & -0.6773 \\
\cline { 2 - 7 } & $\alpha_{M_{G}}$ & 0.2452 & 0.4502 & 0.5821 & 0.6711 & 0.7346 \\
\cline { 2 - 7 } & $\alpha_{M_{Q}}$ & 0.0813 & 0.0672 & 0.0553 & 0.0466 & 0.0401 \\
\hline \multicolumn{2}{|c|}{ Reliability index $\beta$} & 3.7245 & 3.3942 & 3.0252 & 2.6884 & 2.3988 \\
\hline
\end{tabular}




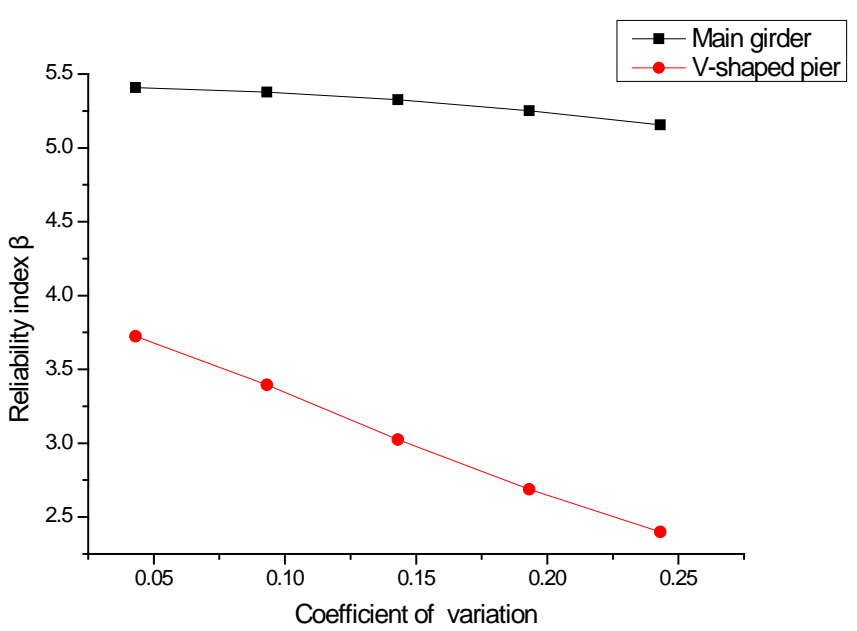

Fig.4. Dead load effect parameter analysis

In the analysis of V-shaped continuous girder bridge, from Table 7, Table 8 and Figure 4, it can be seen that the proportion of dead load in bridge usually accounts for a large proportion, and the variability of dead load effect is not very significant to the reliability index of main beam. But with the change of the coefficient of variation of the dead load effect, the reliability index of V-shaped decreased by 36\%. From the sensitive factor, effect of dead loads on the reliability index is still dominant, with the increase of load variation coefficient, the influence on reliability index gradually increased, and the ability to influence the live load effect gradually weakened.

\section{Effect of variation coefficient of live load on reliability}

In order to study the effect of live load effect coefficient on reliability, the coefficient of variation of live load effect is in the range of $0.0862 \sim 0.2862 / 0.05$. The reliability index of V-shaped continuous beam bridge is calculated by the first order two moment method. The results are shown in Table 9 and Table 10.

Tab.9. Parameter analysis of live load effect of main beam

\begin{tabular}{|c|c|c|c|c|c|c|}
\hline \multicolumn{2}{|c|}{ Coefficient of variatio } & 0.0862 & 0.1362 & 0.1862 & 0.2362 & 0.2862 \\
\hline \multirow{3}{*}{ Sensitivity coefficient } & $\alpha_{M_{R}}$ & -0.7439 & -0.6307 & -0.5628 & -0.5151 & -0.4788 \\
\cline { 2 - 7 } & $\alpha_{M_{G}}$ & 0.0552 & 0.0403 & 0.033 & 0.0285 & 0.0254 \\
\cline { 2 - 7 } & $\alpha_{M_{Q}}$ & 0.666 & 0.775 & 0.8259 & 0.8566 & 0.8776 \\
\hline \multicolumn{2}{|c|}{ Reliability index $\beta$} & 5.4086 & 4.6944 & 4.1681 & 3.7679 & 3.4519 \\
\hline
\end{tabular}

Tab.10. Parameter analysis of live load effect of V-shaped pier

\begin{tabular}{|c|c|c|c|c|c|c|}
\hline \multicolumn{2}{|c|}{ Coefficient of variatio } & 0.0862 & 0.1362 & 0.1862 & 0.2362 & 0.2862 \\
\hline \multirow{3}{*}{ Sensitivity coefficient } & $\alpha_{M_{R}}$ & -0.9661 & -0.9604 & -0.9503 & -0.9342 & -0.9109 \\
\cline { 2 - 7 } & $\alpha_{M_{G}}$ & 0.2452 & 0.2427 & 0.2382 & 0.2312 & 0.2214 \\
\cline { 2 - 7 } & $\alpha_{M_{Q}}$ & 0.0813 & 0.1372 & 0.2007 & 0.2718 & 0.3482 \\
\hline \multicolumn{2}{|c|}{ Reliability index $\beta$} & 3.7245 & 3.7139 & 3.6925 & 3.6586 & 3.6113 \\
\hline
\end{tabular}




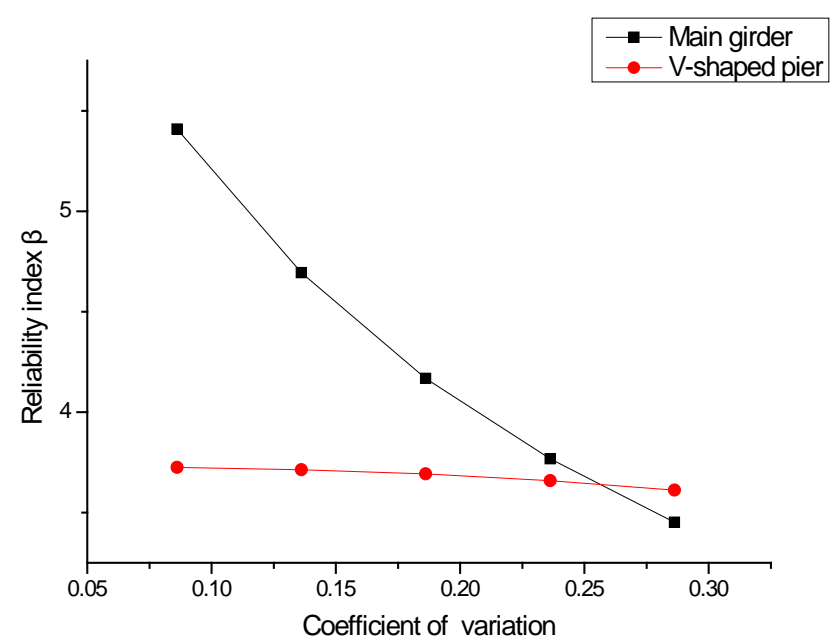

Fig.5. Live load effect parameter analysis

It can be seen from Table 9, Table 10 and Figure 5 that under the intensive operation of the vehicle, the variability of the live load has little effect on the V-shaped pier reliability index, and the influence of the reliability of the main beam can not be neglected. Its reliability index fell by about $36 \%$. Through the analysis of the sensitivity coefficient, it can be seen that the influence of the live load on the reliability index of the main section is still significant. For the V-shaped piers, the influence degree of the sensitivity coefficient is not particularly obvious as the variation coefficient of live load increases, The influence of resistance factors on V-shaped pier reliability is dominant. Therefore, in the operation of such bridges, to strengthen the vehicle load control, as well as the main beam and V-shaped pier maintenance, testing, to ensure long-term use of the bridge performance and durability.

\section{Conclusion}

Based on the reliability theory of engineering structure, JC method is used to analyze the reliability of the critical section bending failure mode of $\mathrm{V}$-shaped continuous beam bridge, and the following conclusions are obtained:

(1) The cross section reliability index of the beam section and the V-shaped pier increases with the loading effect of the cross section, and conforms to the design intention. When analyzing the reliability of V-shaped structure, the reliability index of V-shaped pier top section is lower than that of bottom section, so the top section and reinforcement of V-shaped pier can be optimized.

(2) The prestressed V-shaped pier continuous beam section, the resistance to the reliability index of the main beam and V-shaped pier has a greater impact. Through analysis, in the reference period of bridge design, the load bearing capacity of bridge under constant load is relatively large, and the influence of constant load effect variability on the reliability of main beam is negligible, but it has great influence on the reliability of V-shaped pier In the dense operation state, the proportion of live load effect is not very large, but the influence of the reliability of the main beam is very significant. For the V-shaped pier section, with the increase of the coefficient of variation, the reliability index of $\mathrm{V}$-shaped pier is very small, from the sensitivity coefficient, the resistance factor always occupies the main position which affects the reliability of V-shaped pier.

(3) Prestressed V-shaped continuous beam bridge is widely used in urban landscape bridge construction in recent years with its unique structure, force form and construction method. Due to its unique characteristics, it can improve the spanning ability of the bridge to some extent. At the same time, the increase of span causes the decrease of the stiffness of the main beam and the V-shaped pier, so the study on the reliability of prestressed V-shaped continuous beam bridge is very necessary to improve the design theory, optimize the structure design and ensure the safety and maintenance during operation. 


\section{References}

[1] LI Xiao-ke ,LIU Shi-ming. V Type Pier Continuous Rigid Frame Bridge[M] China Water \& Power Press,2014

[2] SONG Gui-feng, LOU Zhuang-hong, ZhONG Wen-xiang.Pre-stressed Concrete V-shape Strut-framed Bridge in China [J]. Journal of Highway and Transportation Research and Development, 2003, 20(2): 34-38.

[3] HU Feng-qiang. Spatial Analysis and Experimental Study of V Continuous Rigid Frame Bridge with Prestressed Concrete [D] Zhejiang University,2003

[4] LIU Shi-ming, YANG Jian-zhong, YANG Zhu-lin. Structural Design Analysis of Prestressed Concrete Continuous Rigid Frame Bridge with V shaped Pier[J] .Journal of North China Institute of Water Conservancy and Hydroelectric Power,2009,30(5):40-43.

[5] LI Guo-liang, LIU Zhao. Study on the Demolishment Sequence of Scaffolds for the Inverted-triangle Area of the Rigid-frame Bridges with V-piers[J]. Journal of Highway and Transportation Research and Development, 2005, 22(8): 95-101.

[6] JIANG Zheng-wen ,WAN Shui. Analysis of Static Reliability of Continuous Rigid-Frame Bridge Based on Hybrid Simulation Method [J] . Bridge Construction, 2015 , 45(3):26-31.

[7] LIU Yang, DING Xin-hai, LU Nai-wei. Research on Time-varying Reliability of Long-span Continuous Rigid Frame Bridge During Construction Period Based on Adaptive MC Method[J] . Journal of Transport Science and Engineering, 2012 , 28(4):25-31.

[8] LIU Yang, LU Nai-wei.Analysis on System Reliability of Rigid-Fram Bridge Based on Response Surface Method[J] . Journal of Transport Science and Engineering, 2010 , 26(4):24-29.

[9] ZHANG Ye-ping . Research on the Reliability of Continuous Girder Bridge System[D] Department of Municipal Engineering, HeFei University of Technology,2004

[10] ZHAO Guo-fan. Reliability Theory and Its Applications for Engineering Structures[M]Dalian University of Technology Press[M] . Dalian: Dalian University of Technology Press,1996

[11] LI Yang-hai, BAO Wei-gang ,GUO Xiu-wu,et al. Reliability and Probability Limit State Design of Highway Bridge Structures [M].Beijing:China Communications Press, 1997.

[12] ZHANG Jian-ren, LIU Yang. Structural Reliability Theory and Its Application to Bridge Engineering[M].Beijing: China Communications Press, 2002.

[13] GB/T50283-1999,Unified standard for reliability design of highway engineering structures[S].Beijing: China Planning Press,1999 